\title{
FIRE SAFETY OF CLT BUILDINGS IN NEW ZEALAND AND AUSTRALIA
}

\author{
Andrew H. Buchanan* \\ Principal \\ PTL Structural Timber Consultants \\ Christchurch, New Zealand \\ E-mail: a.buchanan@ptlnz.com \\ Andrew Dunn \\ CEO \\ Timber Development Association (NSW) \\ Sydney, New South Wales, Australia \\ E-mail: andrewdunn@tdansw.asn.au \\ James O'Neill \\ Branch Manager \\ Holmes Fire \\ Brisbane, Queensland, Australia \\ E-mail: james.oneill@holmesfire.com \\ Dennis Pau \\ Post-Doctoral Fellow (Fire) \\ University of Canterbury \\ Christchurch, New Zealand \\ E-mail: dennis.pau@canterbury.ac.nz \\ (Received September 2017)
}

\begin{abstract}
This article summarizes the design procedures for ensuring fire safety in cross laminated timber (CLT) buildings in Australia and New Zealand, with reference to the Building Codes in both countries. New Zealand and Australia are located close together geographically and have similarities in some areas of building control, but prescriptive code requirements are often very different. There is a small but growing local CLT industry, but CLT materials for large projects are imported from Europe.
\end{abstract}

Keywords: Fire, CLT, cross laminated timber, buildings, regulations, codes, Australia, New Zealand.

\section{INTRODUCTION}

This article on fire safety in New Zealand and Australia is a companion article to other similar articles considering the fire safety of cross laminated timber (CLT) buildings in several different parts of the world. New Zealand and Australia are located close together geographically and have similarities in some areas of building controls, but prescriptive code requirements are often very different between the two countries.

\footnotetext{
* Corresponding author
}

There are two manufacturers of CLT in the two countries. The larger of the two companies is XLam Ltd., located in Nelson, New Zealand, with a second much larger factory under construction in Woodonga, New South Wales, Australia. The other local producer is CrossLam Australia in Western Australia, now in the start-up phase and producing small volumes of material. Most of CLT production is from radiata pine, with smaller quantities of Douglas fir. Current volumes of CLT produced are for small jobs in New Zealand and Australia, whereas the CLT for larger jobs is being imported from Austria. No CLT imports from North America are known of. 


\section{GUIDANCE AVAILABLE TO PRACTITIONERS}

Basic guidance comes from the building code requirements. There is no industry guidance available on the specific design of CLT structures. Design guidance is predominately obtained through CLT suppliers and manufacturers. Because XLam is the primary CLT manufacturer in this region, many designers rely on the XLam Fire Design Guide (XLam 2017). This will change as more CLT manufacturers enter the region. Most structural fire engineers have access to the book Structural Design for Fire Safety (Buchanan and Abu 2017) which includes guidance for structural fire design of CLT along with other timber materials, largely based on the requirements of Eurocode 5 (CEN 2004).

Designers of imported European CLT have access to the European Technical Approvals (ETAs) and supporting information from each specific manufacturer.

The Australian timber industry provides generic information through its WoodSolutions technical guides that includes information on the fire design of mass timber systems, including CLT. The information is generally related to the recent code change that allows apartment and office buildings up to a height of $25 \mathrm{~m}$.

\section{CURRENT CODE REQUIREMENTS, ALTERNATIVE MEANS, AND PERFORMANCE-BASED DESIGN}

In New Zealand, Section $\mathrm{C}$ of the New Zealand Building Code (NZBC) specifies performance requirements for fire safety in buildings. These requirements can be met in three alternative ways:

1. The most common option is an Acceptable Solution, being a prescriptive design in accordance with Building Code Documents, C/AS1-C/AS7 (MBIE 2016).

2. The second option is design using a Verification Method, C/VM2 (MBIE 2014), which specifies a number of design inputs for performancebased fire design calculations that will be carried out by the designer. Design using C/VM2 will normally require peer review by an independent expert.
3. The final option is an Alternative Solution with evidence to show that the design meets the performance requirements of the Building Code. In many cases, the approving authority will request submission of a peer review by an independent expert.

In Australia, a similar model is followed to achieve compliance with the National Construction Code. The Performance Requirements of the Building Code of Australia (BCA) may be satisfied by applying either of the following, or a combination of both:

1. A Deemed-to-Satisfy Solution, which complies with the prescriptive requirements of the BCA known as the Deemed-to-Satisfy Provisions;

2. A Performance Solution (Alternative Solution), which must be demonstrated as being at least equivalent to the Deemed-to-Satisfy Provisions, which is determined via the approved assessment methods. The four assessment methods are Documentary Evidence, Verification Methods, Expert Judgment, and comparison with the Deemed-to-Satisfy Provisions.

The Solution is approved by an appropriately qualified approval authority, and involvement of the fire brigade to provide comments is commonplace; however, fire brigade input is generally not legislatively binding. Peer reviews for fire-engineered performance solutions are also commonly sought from the approval authority in the case of tall or innovative buildings.

\section{Compartmentation and Floor Areas}

CLT walls and floors are often required to provide the barriers for compartmentation. These are specified in the fire resistance requirements. In New Zealand, the prescriptive Acceptable Solutions impose a maximum $5000 \mathrm{~m}^{2}$ firecell floor area limit for non-sprinkler-protected buildings and the floor area is unlimited with sprinkler protection. A design approach adopting either the Verification Method, C/VM2, or an Alternative 
Solution has no limit in regard to firecell floor area. In Australia, there are limits on floor areas and building volume but they are related to limiting fire compartment size, and can easily be dealt with by fire-rated walls and floors.

\section{Combustibility}

The NZBC has no specific requirements for "noncombustibility" of building materials. Any combustible materials may be used anywhere within a building, provided that the requirements for fire resistance and surface spread of flame are met.

Before 2016, the BCA Deemed-to-Satisfy provision restricts the use of combustible materials within parts of a building performing certain critical functions. In all of these cases, these requirements will also apply to CLT. For buildings greater than two storeys in height and depending on building use, this includes but is not limited to the following areas:

1. External walls and fire resisting walls must be noncombustible.

2. Internal load-bearing walls (including shafts) must comprise concrete or masonry.

In 2016 the regulations were amended to allow a timber option termed "fire-protected timber." Fire-protected timber is timber which is covered with a noncombustible fire-protective covering which will protect the timber from charring for a defined period. The period depends on whether it is lightweight timber framing or mass timber such as CLT. Generally, an internal wall comprising fire-protected timber is limited to residential and office buildings under a certain height (approximately eight storeys) and requires the installation of an automatic sprinkler system throughout the building, noncombustible insulation, and barriers within the cavities of fire resisting elements.

As described previously, combustible column, beam, floor, and roof construction may be designed under the Deemed-to-Satisfy Provisions of the BCA, without the application of a performance solution. However, when considering CLT construction, the requirement for fireprotected timber necessitates passive proprietary protection of the CLT in addition to the application of a performance solution for taller buildings.

\section{Early Fire Hazard Issues with Exposed Timber Surfaces}

New Zealand-NZBC Clause C3-Fire Affecting Areas beyond the Fire Source (DBH 2012) prescribes surface finish requirements for internal linings, including wall, ceiling, and flooring in different types of occupancies. These clauses are currently under review to allow some flexibility in design, especially in crowd-related occupancies where the fire and life safety risks in terms of occupant load, combustible fuel areas, and level of fire protection can vary substantially. There are three group numbers, 1, 2, and 3, determined on test results in accordance with ISO 5660.1 or ISO 9705, which are the wall and ceiling performance criteria allowed by NZBC. The installation of sprinkler protection allows a relaxation in the surface finish requirements, and the smoke production limit is waived.

NZBC requires Group 1 wall and ceiling linings in sleeping occupancies providing care and detention, and in protected paths (smoke lobbies) and safe paths (stairwells). With sprinkler protection, this can be increased to Group 2. For crowd occupancies and residential sleeping use (including temporary accommodations), the minimum requirement is Group 2. Sprinkler protection will relax the requirement for wall lining, but not ceiling linings, to Group 3, on the basis that sprinkler spray typically does not protect the ceiling. Most other spaces within a building need to achieve a minimum Group 3 surface. The surface requirements for Group 3 can be met with normal wood and typical paint finishes. In the absence of testing, NZBC accepts an inherent rating of Group 3 for wood products with a minimum thickness of $9 \mathrm{~mm}$ and minimum density of $400 \mathrm{~kg} / \mathrm{m}^{3}$. Expensive intumescent applied coatings are required to achieve Group 1 
and 2 finishes, so wood is often covered up in those situations with a more cost-effective solution such as plasterboard lining. Nevertheless, NZBC does exempt major structural timber elements from the surface finish requirements, including columns, beams, and shear walls not more than $3 \mathrm{~m}$ wide, constructed from solid wood, glulam, or laminated veneer lumber.

In Australia a similar scheme is followed, with an increasing level of safety required for areas within a building which provide critical or essential functions (such as fire control rooms, fire-isolated exits, and public areas to a lesser degree). Concessions in the fire hazard properties of linings, materials, and assemblies to account for the presence of an automatic sprinkler system within the building are also provided, with most areas (excluding fire control rooms and fire-isolated exits) allowing a Group 3 wall and ceiling lining material for most building occupancies. Timber use where Groups 1 and 2 are required is difficult as fire retardants applied by coating methods are not allowed.

\section{FIRE RESISTANCE FOR PRIMARY STRUCTURE}

\section{Structural Design Code in Nonfire Conditions}

Although the design of heavy timber structures is addressed in the respective timber standards of Australia, AS 1720.1 (SA 2014), and New Zealand, NZS 3603 (NZS 2007), no specific mention is made regarding the design and detailing of CLT because the CLT industry is not yet considered to be sufficiently mature. However, timber products not listed may still be used if their properties are established by creditable testing and evaluation. There is also no reference to CLT in the draft New Zealand standard NZS/ AS 1720 (SNZ 2017) which is currently out for public comment. These standards are expected to be combined into a joint Australian/New Zealand standard in due course.

\section{Required Level of Fire Resistance}

The building codes in both countries specify the fire resistance required in different situations. In most cases these are specified explicitly, but in New Zealand it is possible in some special cases or via the application of Verification Method C/ VM2 or an alternative solution to determine the required fire resistance by using the Eurocode time equivalent formula, taking into account the ventilation and fuel load in the fire compartment.

In Australia, a Performance Solution can be developed to reduce the fire resistance of any building area or part; however, no such methods are explicitly endorsed by the code, the choice of which is at the designer's discretion.

The Australian building regulations have specific requirements for all materials used in construction and for all applications other than single family housing, to have minimum fire hazard properties determined by AS/NZS 1530.3.

Required fire resistance ratings in the NZBC are generally low by comparison with other international standards, being $60 \mathrm{~min}$ for protection of means of escape and internal fire spread, and this includes residential buildings, care and detention facilities, crowd spaces, business and storage spaces, and car parks. For protection of neighboring property, 60-min fire rating is still applicable in some cases but higher fire resistance rating of $120 \mathrm{~min}$ is expected for crowd and lowlevel storage occupancies (less than $3 \mathrm{~m}$ ) whereas $180 \mathrm{~min}$ is expected for high-level storage (greater than $3 \mathrm{~m}$ ). The Code allows these prescribed fire resistance ratings to be halved if an automatic fire sprinkler system up to the New Zealand Sprinkler Standard, NZS 4541, is voluntarily installed, ie greater than the NZBC minimum level of fire protection, leading to fire resistance of 30,60 , or $90 \mathrm{~min}$.

In most situations, roof structures are not required to have any fire resistance, for buildings of any height or material. This can create a problem for the stability of exterior walls which have lateral restraint provided by the roof under normal lateral loading from wind or earthquake. A draft amendment to the Acceptable Solution will allow such exterior walls to be pulled inward as the roof collapses during fire exposure. 
By contrast, the BCA has much greater requirements for fire resistance in buildings, with the generic requirements for buildings ranging from 30 to $240 \mathrm{~min}$, and a minimum requirement of at least $90 \mathrm{~min}$ for many taller structures. No concessions to these fire resistance requirements are provided for the installation of an automatic fire sprinkler system in general, with car parks being a notable exception, allowing a reduction to $60 \mathrm{~min}$ from the required $120 \mathrm{~min}$.

Roof structures are not required to achieve any fire resistance for residential and low-rise buildings, or any building provided with an automatic sprinkler system, provided that the roof covering is noncombustible.

\section{Meeting Fire Resistance Requirements}

In both countries, the fire resistance of timber structural members is calculated in accordance with the charring calculations specified in AS/NZS 1720.4 (SA 2017). This is a new joint standard, still in draft form, being a recent merger of AS 1720.4 (SA 2006) and the fire clauses of NZS 3603 (SNZ 2007). The new standard AS/ NZS 1720.4 applies specifically to sawn timber, glulam, plywood, and LVL, but does not mention mass timber or CLT.

In the absence of code requirements for CLT, structural calculations for the fire resistance of CLT panels are usually made with reference to test results or ETAs provided by the manufacturers. These calculations and supporting documents become part of an Alternative Solution. The level of detail and the amount of supporting information depends on what is required by the approving authority. In many cases, the approving authority will request submission of a peer review by an independent expert stating that the Alternative Solution design meets the performance requirements of the Building Code.

For imported CLT, there is a problem with consistency of results from fire resistance tests performed in different countries. This is because of a number of factors:
- Minor differences between the test methods in ISO 834, ASTM E119, and AS 1530.4.

- Differences between the load levels used in the tests; eg most European fire resistance tests of structural walls have used very low levels of vertical loading.

- Poor availability of test reports, some of which are considered to be confidential proprietary information.

- Inconsistency in the level of information in ETAs.

Some of these issues are being solved as more manufacturers carry out fire resistance tests in Australia, as more test reports enter the public domain, and as European manufacturers collaborate to provide more consistent design methods.

\section{PROTECTION OF STRUCTURAL TIMBER BY LINING MATERIALS}

Guidance is given in AS/NZS 1720.4 for calculating structural performance of timber members protected by lining materials such as gypsum boards. Calculations require information from gypsum board manufacturers on the time to reach $300^{\circ} \mathrm{C}$, and the time to falloff which is dependent on the specific board makeup and fixing of the board to the CLT. Therefore the information provided is not comprehensive, so building designers often have to develop their own engineered solutions for each building on a case-by-case basis.

One importer of Austrian CLT imports a thin nonstructural CLT panel which can be used as a decorative wood layer, placed over the gypsum board fire protection to the structural CLT, to retain the CLT appearance where a simple charring calculation on the unprotected CLT panel is insufficient to achieve the required fire resistance.

\section{CONNECTIONS}

In New Zealand and Australia, there are no modern design rules for structural fire design of connections in any structural timber, including CLT. The only prescribed calculations are in 
AS/NZS 1720.4 which requires all steel fasteners to be protected from fire by timber cladding, timber plugs, or similar, without any details suitable for modern structures.

Consequently, structural fire design of connections is often undertaken differently for every job, with only enough detail used to satisfy the relevant local authority (or peer reviewer), using a mixture of calculations from first principles, information from manufacturers of CLT or fasteners, or design methods from Eurocode 5.

\section{CONCLUSIONS}

In conclusion, although a framework for the design of timber buildings is provided in both Australia and New Zealand, the traditional approach has been to develop solutions for each building on a case-by-case basis. As such, the available guidance is less prescriptive and restrictive than in other countries, with a heavy reliance on the design team to produce an acceptable solution.

Although prescriptive methods are provided by the code environment, no restrictions are placed on the application of an Alternative Solution design, such that any building design may be justified by designers provided that the level of safety demonstrated by the design team is found to be acceptable by the approval authorities. This inherently allows for a great degree of freedom in design and also places a heavy reliance on the competence of all parties involved in the design and building processes.

\section{REFERENCES}

Buchanan AH, Abu AK (2017) Structural design for fire safety, 2nd Ed. John Wiley \& Sons, UK.

CEN (2004) Eurocode 5: Design of timber structures-Part 1-2: General - Structural fire design. EN 1995-1-2. European Committee for Standardization, Brussels, Belgium.

DBH (2012) Extract from the New Zealand building code: Clauses C1-C6 protection from fire, clause A3 building importance levels. Department of Building and Housing.

MBIE (2014) C/VM2. Verification method: Framework for fire safety design, for New Zealand building code clauses C1-C6 protection from fire. Ministry of Business, Innovation and Employment.

MBIE (2016) C/AS1-7. Acceptable solution for buildings, for New Zealand building code clauses C1-C6 protection from fire. Ministry of Business, Innovation and Employment.

SA (2006) AS 1720.4 - 2006. Timber structures, part 4: Fire resistance for structural adequacy of timber elements. Standards Australia.

SA (2014) AS 1720.1 - 2006. Timber structures, part 1: Design methods. Standards Australia.

SA (2017) AS/NZS 1720.4 - 2017. Timber structures, part 4: Fire resistance of timber elements. Draft for public comment. Standards Australia.

SNZ (2007) NZS 3603:1993, with amendments 1 to 4 . Timber structures standard. Standards New Zealand, Wellington, New Zealand.

SNZ (2017) NZS/AS 1720. Timber structures standard. Draft for public comment. Standards New Zealand, Wellington, New Zealand.

XLam (2017) Designing with XLam laminated timber. Fire design guide. www.xlam.co.nz. 